Portland State University

PDXScholar

Summer 2015

\title{
Community-Based Participatory Research to Adapt Health Measures for Use by People With Developmental Disabilities
}

\author{
Christina Nicolaidis \\ Portland State University \\ Dora Raymaker \\ Portland State University \\ Marsha Katz \\ Autistic Self Advocacy Network \\ Mary Oschwald \\ Portland State University \\ Rebecca Goe \\ University of Montana
}

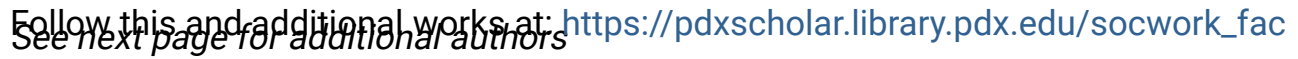

Part of the Health Services Research Commons

Let us know how access to this document benefits you.

\section{Citation Details}

Nicolaidis, C., Raymaker, D., Katz, M., Oschwald, M., Goe, R., Leotti, S., ... \& Powers, L. E. (2015).

Community-based participatory research to adapt health measures for use by people with developmental disabilities. Progress in community health partnerships: research, education, and action, 9(2), 157-170.

This Article is brought to you for free and open access. It has been accepted for inclusion in Social Work Faculty Publications and Presentations by an authorized administrator of PDXScholar. Please contact us if we can make this document more accessible: pdxscholar@pdx.edu. 


\section{Authors}

Christina Nicolaidis, Dora Raymaker, Marsha Katz, Mary Oschwald, Rebecca Goe, Sandra Leotti, Leah Grantham, Eddie Plourde, Janice Salomon, Rosemary B. Hughes, Laurie E. Powers, and Partnering With People With Disabilities to Address Violence Consortium 


\section{Community-Based Participatory Research to Adapt Health Measures for Use by People With Developmental Disabilities}

Christina Nicolaidis, MD, MPH ${ }^{1,2}$, Dora Raymaker, $\mathrm{PhD}^{3}$, Marsha Katz ${ }^{4}$, Mary Oschwald, $\mathrm{PhD}^{1}$, Rebecca Goe ${ }^{4}$, Sandra Leotti ${ }^{1}$, Leah $\mathrm{Grantham}^{4}$, Eddie Plourde ${ }^{5}$, Janice Salomon ${ }^{6}$, Rosemary B. Hughes ${ }^{4}$, Laurie E. Powers, $\mathrm{PhD}^{1}$, and

The Partnering With People With Disabilities to Address Violence Consortium*

(1) Regional Research Institute for Human Services, School of Social Work, Portland State University; (2) Departments of Medicine and Public Health \& Preventive Medicine, Oregon Health \& Science University; (3) Autistic Self Advocacy Network; (4) Rural Institute, University of Montana; (5) Self-Advocacy Coalition of Oregon (formerly Self Advocates as Leaders); (6) Missoula People First

* The Partnering With People With Disabilities to Address Violence Consortium includes: Principal Investigator: Rosemary Hughes, PhD, (University of Montana); Co-Principal Investigators: Laurie Powers, PhD (Portland State University), Christina Nicolaidis, MD, MPH (Oregon Health \& Science University); Project Managers: Marsha Katz, MA (University of Montana), Mary Oschwald, PhD (Portland State University); Community Organizational Representatives to the Steering Committee: Darren Larson (Summit Independent Living Center), Eddie Plourde (Self-Advocacy Coalition of Oregon, formerly Self Advocates as Leaders), Dora Raymaker, PhD (Autistic Self Advocacy Network), Lisa Howard (Bitterroot People First); Community Advisory Board Members: Elesia Ashkenazy, Leanne Beers, Mark Boatman, Gail Bernice Gardner, Nicole Gray, Leah Grantham, James Larocque, Mary Millin, Sherrie Osbourne, Janice Salomon, Albert Star, Andrew Tedlow, Annie Wallington; Consultants: Mary Ann Curry, RN, DNSc, Susan Robinson-Whelen, PhD; Research Assistants: Rebecca Goe, Sandra Leotti, Emily Lund.

\section{What is the Purpose of this Study/Review?}

- The Partnering with People with Developmental Disabilities to Address Violence project is a collaboration between academic researchers and leaders with developmental disabilities at two sites, one in Montana and the other in Portland, Oregon. We used a community-based participatory research approach to study the relationship between health, disability, and interpersonal violence in people with developmental disabilities. In addition to analyzing these relationships in the main study, we also examined how we:

- Developed, adapted, and pilot tested the survey measures and study materials so that they could be validly used with adults with developmental disabilities; and

- Worked together to successfully include people with developmental disabilities as equal partners in all parts of the research process.

- This brief focuses on our measurement adaptation and collaboration aims.

What Is the Problem?

- People with developmental disabilities are often not included as participants in research because of a number of ethical and practical challenges.

- Quantitative measures (surveys) are often inaccessible to people with developmental disabilities. Surveys that are valid in the general population may not be valid in the developmental disability population. Further, researchers often lack strategies for how to make surveys and other study materials accessible and valid for people with developmental disabilities.

- Community-based participatory research is known to be an effective way of addressing similar issues in other populations, such as people from racial or ethnic minority backgrounds. However, community-based participatory research has rarely been used with people with developmental disabilities. 
What Are the Findings?

- Attention to structure, communication, and process is necessary to balance power between academic researchers and community members.

- In-person meetings provided a common ground for communication.

- Communication accommodations included using accessible language, providing American Sign Language (ASL) interpreters, describing images, and reading written materials out loud.

- Other effective accessibility guidelines included respecting each other's needs, making materials available before meetings and holding pre-meetings to go over materials, providing summaries of actions and decisions before and after meetings, establishing a formal decision-making process, providing sensory objects, providing stipends for participating in meetings, reimbursing for transportation, inviting personal assistants to attend meetings, and implementing continuous check-ins and improvements.

- Our measurement adaptation process was done by:

- Collaboratively choosing surveys that would need the least amount of adapting and then splitting them up between the two sites (Montana and Oregon) for the main adaptation work;

- Having a smaller group of self-advocates and academic researchers at Site One fix more obvious issues;

- Working on the adaptation as a larger group at Site One;

- Passing the adapted measure to the larger group at Site Two for a final check; and

- Having the principal investigators make a final decision regarding any differences in adaptation recommendations by the two sites.

- Adaptation guidelines we used were:

- Only change something if it is not understandable;

- Do not change the meaning of anything; and

- Do not remove questions or add questions.

- Adaptation strategies we used were to:

- Make language more simple;

- Make language more specific;

- Use "hot link" boxes to definitions or examples where it was not possible to simplify or specify language while still keeping its original meaning; and

- Use pictures to illustrate difficult ideas and response options (e.g., smiley faces to indicate a scale from "not at all bothered or upset" to "extremely bothered or upset"). Use of this strategy enabled us to keep all of the original response formats.

- We used a collaborative process to create and adapt our other study materials, such as consent forms and recruitment fliers.

- People with intellectual disabilities and people on the autism spectrum may have conflicting accessibility needs around language. Compromises need to be found to adapt language to be both simple and specific for surveys to be used by both populations.

- People with a wide range of developmental disabilities were able to correctly paraphrase the meanings of our adapted surveys, and found the pictures were helpful. Those who were shown the original and adapted items either preferred the adapted version or felt they were both equally easy to understand.

- Our adapted health measures for depression, posttraumatic stress disorder, social support, and physical health symptoms had similarly high reliability when used in our population of people with developmental disabilities as the original measures when used in the general population. There was no difference in reliability between participants who identified as having a cognitive disability and those who identified as being on the autism spectrum. Our adapted measure for perceived stress did not have high reliability; this may be in part because it is a four-item survey. 
- Researchers interested in conducting research with people with developmental disabilities.

- People with developmental disabilities and self-advocacy organizations interested in partnering with researchers to address a community concern.

Recommendation for Action

- Anyone interested in survey research with people with developmental disabilities should consider using a communitybased participatory research approach to adapt survey measures, and to create accessible study materials. The strategies listed under Findings can serve as a good starting place for new partnerships. 